NASA/TM-2010-216365

Optical Characterization of a Multipoint Lean Direct Injector for Gas Turbine Combustors: Velocity and Fuel Drop Size Measurements

Christopher M. Heath and Robert C. Anderson

Glenn Research Center, Cleveland, Ohio

Randy J. Locke

Arctic Slope Regional Corporation, Cleveland, Ohio

Yolanda R. Hicks

Glenn Research Center, Cleveland, Ohio 


\section{NASA STI Program . . . in Profile}

Since its founding, NASA has been dedicated to the advancement of aeronautics and space science. The NASA Scientific and Technical Information (STI) program plays a key part in helping NASA maintain this important role.

The NASA STI Program operates under the auspices of the Agency Chief Information Officer. It collects, organizes, provides for archiving, and disseminates NASA's STI. The NASA STI program provides access to the NASA Aeronautics and Space Database and its public interface, the NASA Technical Reports Server, thus providing one of the largest collections of aeronautical and space science STI in the world. Results are published in both non-NASA channels and by NASA in the NASA STI Report Series, which includes the following report types:

- TECHNICAL PUBLICATION. Reports of completed research or a major significant phase of research that present the results of NASA programs and include extensive data or theoretical analysis. Includes compilations of significant scientific and technical data and information deemed to be of continuing reference value. NASA counterpart of peer-reviewed formal professional papers but has less stringent limitations on manuscript length and extent of graphic presentations.

- TECHNICAL MEMORANDUM. Scientific and technical findings that are preliminary or of specialized interest, e.g., quick release reports, working papers, and bibliographies that contain minimal annotation. Does not contain extensive analysis.

- CONTRACTOR REPORT. Scientific and technical findings by NASA-sponsored contractors and grantees.
- CONFERENCE PUBLICATION. Collected papers from scientific and technical conferences, symposia, seminars, or other meetings sponsored or cosponsored by NASA.

- SPECIAL PUBLICATION. Scientific, technical, or historical information from NASA programs, projects, and missions, often concerned with subjects having substantial public interest.

- TECHNICAL TRANSLATION. Englishlanguage translations of foreign scientific and technical material pertinent to NASA's mission.

Specialized services also include creating custom thesauri, building customized databases, organizing and publishing research results.

For more information about the NASA STI program, see the following:

- Access the NASA STI program home page at http://www.sti.nasa.gov

- E-mail your question via the Internet to help@ sti.nasa.gov

- Fax your question to the NASA STI Help Desk at $443-757-5803$

- Telephone the NASA STI Help Desk at 443-757-5802

- Write to: NASA Center for AeroSpace Information (CASI) 7115 Standard Drive Hanover, MD 21076-1320 
NASA/TM-2010-216365

Optical Characterization of a Multipoint Lean Direct Injector for Gas Turbine Combustors: Velocity and Fuel Drop Size Measurements

Christopher M. Heath and Robert C. Anderson

Glenn Research Center, Cleveland, Ohio

Randy J. Locke

Arctic Slope Regional Corporation, Cleveland, Ohio

Yolanda R. Hicks

Glenn Research Center, Cleveland, Ohio

Prepared for the

Turbo Expo 2010

sponsored by the American Society of Mechanical Engineers (ASME)

Glasgow, Scotland, United Kingdom, June 14-18, 2010

National Aeronautics and

Space Administration

Glenn Research Center

Cleveland, Ohio 44135 


\section{Acknowledgments}

This work was supported by the Subsonic Fixed Wing and Supersonics Projects in NASA's Aeronautics Research Mission

Directorate. The authors gratefully acknowledge Changlie Wey for his assistance and guidance. We also thank the CE-5 test crew, especially our technicians Jeff Hamman, Bill Rozman, Harold Redloske, and Tom Ralys.

This work was sponsored by the Fundamental Aeronautics Program at the NASA Glenn Research Center.

Level of Review: This material has been technically reviewed by technical management.

Available from

NASA Center for Aerospace Information 7115 Standard Drive

Hanover, MD 21076-1320
National Technical Information Service 5301 Shawnee Road Alexandria, VA 22312 


\title{
Optical Characterization of a Multipoint Lean Direct Injector for Gas Turbine Combustors: Velocity and Fuel Drop Size Measurements
}

\author{
Christopher M. Heath and Robert C. Anderson \\ National Aeronautics and Space Administration \\ Glenn Research Center \\ Cleveland, Ohio 44135 \\ Randy J. Locke \\ Arctic Slope Regional Corporation \\ Cleveland, Ohio 44135 \\ Yolanda R. Hicks \\ National Aeronautics and Space Administration \\ Glenn Research Center \\ Cleveland, Ohio 44135
}

\begin{abstract}
Performance of a multipoint, lean direct injection (MP-LDI) strategy for low emission aero-propulsion systems has been tested in a Jet-A fueled, lean flame tube combustion rig. Operating conditions for the series of tests included inlet air temperatures between 672 and $828 \mathrm{~K}$, pressures between 1034 and $1379 \mathrm{kPa}$ and total equivalence ratios between 0.41 and 0.45 , resulting in equilibrium flame temperatures approaching $1800 \mathrm{~K}$. Ranges of operation were selected to represent the spectrum of subsonic and supersonic flight conditions projected for the next-generation of commercial aircraft.

This document reports laser-based measurements of in situ fuel velocities and fuel drop sizes for the NASA 9-point LDI hardware arranged in a $3 \times 3$ square grid configuration. Data obtained represent a region of the flame tube combustor with optical access that extends $38.1-\mathrm{mm}$ downstream of the fuel injection site. All data were obtained within reacting flows, without particle seeding. Two diagnostic methods were employed to evaluate the resulting flow path. Three-component velocity fields have been captured using phase Doppler interferometry (PDI), and two-component velocity distributions using planar particle image velocimetry (PIV). Data from these techniques have also offered insight into fuel drop size and distribution, fuel injector spray angle and pattern, turbulence intensity, degree of vaporization, and extent of reaction.

This research serves to characterize operation of the baseline NASA 9-point LDI strategy for potential use in future gas-turbine combustor applications. An additional motive is the compilation of a comprehensive database to facilitate understanding of combustor fuel injector aerodynamics and fuel vaporization processes, which in turn may be used to validate computational fluid dynamics codes, such as the National Combustor Code (NCC), among others.
\end{abstract}

Nomenclature

\begin{tabular}{|c|c|}
\hline MP-LDI & Multi-point Lean Direct Injection \\
\hline LDI & Lean Direct Injection \\
\hline CAEP & Committee on Aviation Environmental Protection \\
\hline ICAO & International Civil Aviation Organization \\
\hline $\mathrm{NCC}$ & National Combustion Code \\
\hline PDI & Phase Doppler Interferometry \\
\hline PIV & Particle Image Velocimetry \\
\hline LTO & Landing-Take-Off Cycle \\
\hline ICCD & Intensified Charge-Coupled Device \\
\hline Nd:YAG & Neodymium-Doped Yttrium Aluminum Garnet \\
\hline UHC & Unburned Hydrocarbon \\
\hline $\mathrm{HC}$ & Hydrocarbon \\
\hline FWHM & Fixed Width at Half Maximum \\
\hline $\mathrm{CO}$ & Carbon Monoxide \\
\hline $\mathrm{NO}_{\mathrm{x}}$ & Oxides of Nitrogen \\
\hline RMS & Root mean square \\
\hline$\Phi \quad[-]$ & Equivalence Ratio, fuel-to-air basis \\
\hline $\mathrm{X} \quad[\mathrm{mm}]$ & Axial flow direction \\
\hline $\mathrm{Y} \quad[\mathrm{mm}]$ & Horizontal flow direction \\
\hline $\mathrm{Z} \quad[\mathrm{mm}]$ & Vertical flow direction \\
\hline $\mathrm{U} \quad[\mathrm{m} / \mathrm{s}]$ & Axial velocity component \\
\hline $\mathrm{V} \quad[\mathrm{m} / \mathrm{s}]$ & Horizontal velocity component \\
\hline $\mathrm{W} \quad[\mathrm{m} / \mathrm{s}]$ & Vertical velocity component \\
\hline $\mathrm{D}_{10}[\mu \mathrm{m}]$ & Linear drop diameter \\
\hline
\end{tabular}

Subscripts:

in inlet

T total 


\section{Introduction}

Aviation emissions are becoming an internationally recognized environmental concern as air traffic continues to rise in an effort to keep pace with global economic, military, and private demands. In response, laws regulating pollutant levels are growing progressively stringent as governing organizations continue to tighten existing emission certification standards and adopt new policies for managing the next-generation of aero-propulsion systems. The Committee on Aviation Environmental Protection (CAEP), a subset of the International Civil Aviation Organization (ICAO), is responsible for reviewing engine performance trends and recommending operating practices and standards to further mitigate the impact of civil aviation on global atmosphere and climate. Current ICAO regulations limit ground level emissions of hydrocarbons (HC), carbon monoxide (CO), and oxides of nitrogen $\left(\mathrm{NO}_{\mathrm{x}}\right)$ based on landing and take-off cycle (LTO) operation. Future laws are expected to more closely regulate exhaust products at altitude or impose emission related levies in the form of landing taxes, with collected funds intended for financing research to reduce the environmental impact of civil air transport (Refs. 1 and 2).

Advanced combustion and fuel injection methods will be necessary to overcome the challenges posed by impending emission laws. Aircraft will need to operate within the constraints of increasing regulations while satisfying the potentially complex mission objectives expected of next-generation vehicles. Multi-point lean direct injection (MP-LDI) is a NASA developed low-emission fuel injection technology that appears to assist in meeting the dual requirements of low- $\mathrm{NO}_{\mathrm{x}}$ production and high performance. The strategy was developed to facilitate rapid, stable, and uniform combustion under lean operation, resulting in lower combustor peak flame temperatures and reducing primary emission contributions from the thermal $\mathrm{NO}_{\mathrm{x}}$ mechanism. MP-LDI schemes appear to maintain $\mathrm{CO}$ and unburned hydrocarbon emission levels relative to limits established in the 1996 ICAO standard (Refs. 3 and 4).

The MP-LDI concept incorporates a large number of small scale fuel injectors in place of a conventional, single injector. The reduced scale promotes rapid mixing of fuel and oxidizer, and the conditions at the flame front approach those in a premixed, prevaporized flame. Multiple injectors can be integrated into modules to allow for a variety of fuel staging possibilities appropriate for an LTO engine cycle. MP-LDI was chosen as our fuel injector/mixer test case for validating the National Combustion Code (NCC) because the concept provides low emissions, allows for different fuel staging strategies, and has realistic, complex fluid interactions.

A large number of variables play a role in developing and optimizing low emission fuel injection strategies. Design choices include the number and size of injector elements, whether to use radial or axial air swirlers, swirler angle and direction, and type of fuel nozzle. Tacina et al. (Ref. 4) considered these factors in comparing combustion performance, based on $\mathrm{NO}_{\mathrm{x}}$ and $\mathrm{CO}$ emissions. $3 \times 3,5 \times 5,6 \times 6$, and $7 \times 7$ element arrays were studied. $\mathrm{NO}_{\mathrm{x}}$ emissions were low in all cases and found to decrease with swirl number and combustor operability range.

The MP-LDI concept is currently under evaluation and testing to support future gas-turbine combustor applications. In this study, the multipoint injection strategy has been tested in a square array configuration comprised of nine LDI elements arranged in a $3 \times 3$ grid. This configuration has been designated as the baseline configuration.

Several useful parameters for defining fuel injection operation and emission levels include liquid and gas phase velocities, turbulence intensity, and fuel vaporization. Optical and laser-based diagnostics have been employed to capture this information for the 9-point hardware at test points simulating subsonic and supersonic flight conditions. This document focuses on reporting and comparing results from two diagnostic techniques with emphasis on (1) developing a database for verifying computational combustion flow models and (2) assessing and refining diagnostic techniques specifically for application to our facility which operates at realistic aircraft combustor conditions.

We describe here our efforts to use two complementary, laser-based optical techniques to acquire and compare velocity distributions and RMS measurements. Phase Doppler interferometry (PDI) provided the means to capture three-component velocity fields, turbulence intensity and injector full cone spray angle. Using planar particle image velocimetry (PIV) we were able to acquire two-component fuel spray velocity distributions as well as injector spray angle. The results from both methods were very similar in all cases where direct comparison was possible.

In this work all experimental data were acquired using non-preheated Jet-A fuel supplied to the combustor through the 9-point lean direct injection (LDI) hardware.

\section{Facility}

The baseline hardware was tested in a high temperature and high pressure flametube combustor rig with partial optical access directly downstream of the fuel injection site. The experimental facility and diagnostic instrumentation offered the combined unique ability to perform non-intrusive optical and laser based techniques demonstrating fluid and chemical processes during combustion. The test cell in this study was capable of supplying non-vitiated inlet air to the combustor at temperatures between 450 and $1100{ }^{\circ} \mathrm{F}$ (505 to $866 \mathrm{~K}$ ), pressures between 150 and 250 psia (1034 to $1724 \mathrm{kPa}$ ) with flow rates up to $10-\mathrm{lb}_{\mathrm{m}} / \mathrm{s}(4.54 \mathrm{~kg} / \mathrm{s})$. Total equivalence ratios supporting stable lean operation of the flametube were generally between 0.33 and 0.55 depending on the simulated engine conditions. The entire rig was operated remotely and sustained by an adjacent control room and laser facility. 


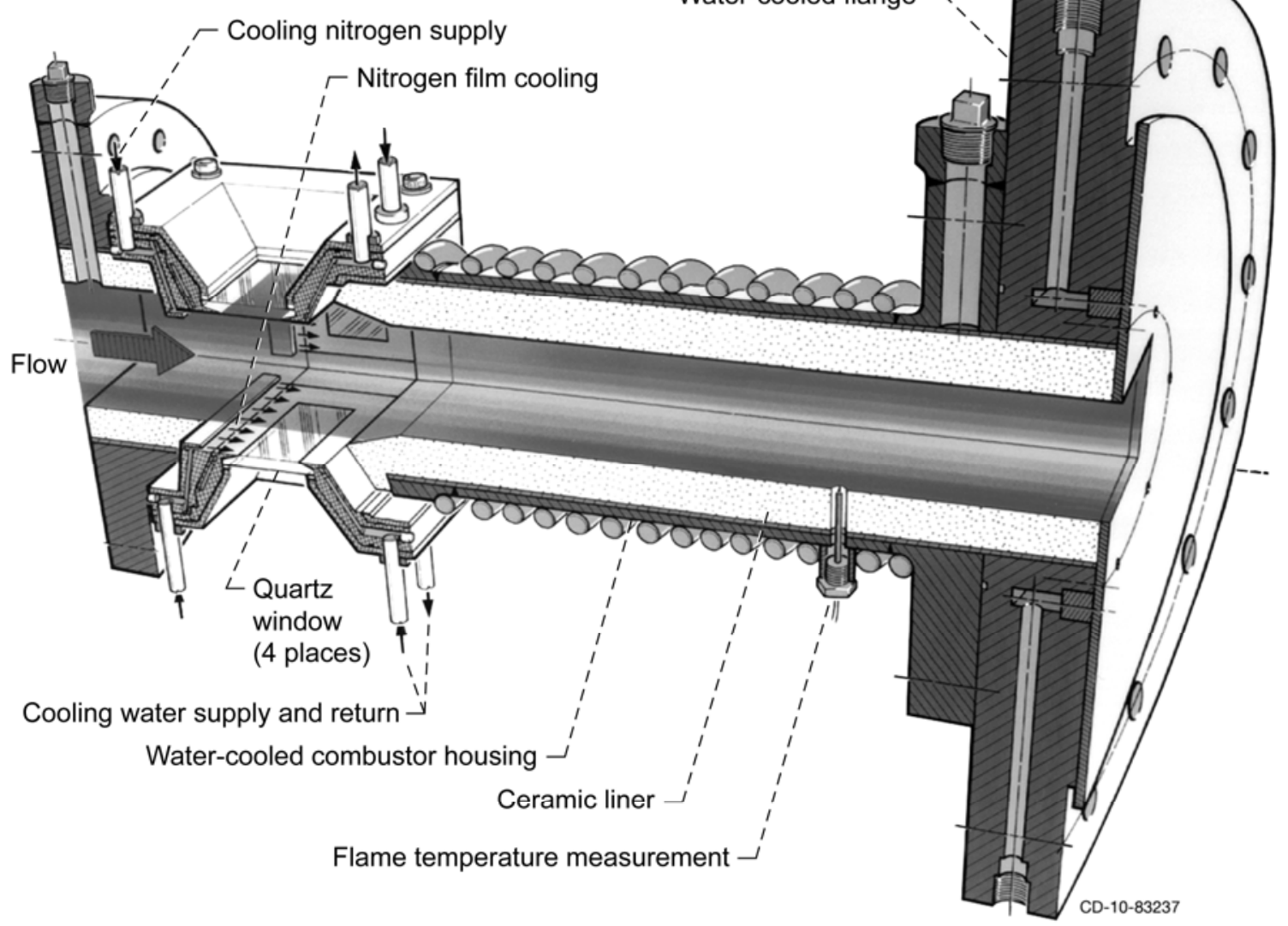

Figure 1.-Schematic drawing that illustrates the optically-accessible flame tube and window assemblies.

An isolated full-section view of the window assembly and aft flametube are displayed in Figure 1. The combustor housing measures $74-\mathrm{cm}$ in length and is lined with an aluminum oxide ceramic to withstand average temperatures reaching $3200{ }^{\circ} \mathrm{F}(2033 \mathrm{~K})$. UV-grade fused silica windows ( 38.1 by $50.8-\mathrm{mm}$ ) are mounted just downstream of the fuel injection site and provide optical access from three sides of the square combustion chamber. The combustion chamber has a cross section measuring 76.2 by $76.2-\mathrm{mm}$. The bottom of the chamber is reserved for a spark igniter system and provides no physical or optical access. The grade of quartz used in the windows offers a minimum light transmission of 80 percent within a spectral range from 180 to $3300-\mathrm{nm}$, making it ideal for supporting optical measurements (Ref. 5). Nitrogen film cooling is used internally to regulate window temperature and accounts for no more than 10 percent by mass of the total inlet air flow. The external housing and downstream flange section are water cooled to reduce thermal and material stresses at high temperature and pressure conditions.

\section{Injector Architecture}

The baseline 9-point test hardware is described in Reference 4 and consists of a $3 \times 3$ injector array measuring 76.2 by 76.2-mm with injectors spaced 25.4-mm (center-to-center).
Each injector element is comprised of a set of six helical, axial vanes angled at $60^{\circ}$ surrounding a simplex-type nozzle that atomizes and injects liquid fuel (Jet-A) at the throat of a converging-diverging venturi. The calculated swirl number is 1.0. A schematic of a single injector element is displayed in the full section view of Figure 2. The array is shown in Figure 3.

\section{Diagnostic Setup and Procedures}

Two optical diagnostic methods were used to interrogate the 9-point LDI combusting flow and acquire a number of critical flowfield parameters. Phase Doppler interferometry (PDI) was used to characterize the vaporization and mixing of the 9-point LDI by providing mean diameter statistics, fuel injector spray angle and pattern, three-dimensional liquid velocity field characteristics, and turbulence levels. Particle image velocimetry (PIV) was used to obtain planar twocomponent fuel velocity distributions further demonstrating directional flow properties and emphasizing interaction zones between injectors. Both PDI and PIV are well-established techniques that have commercially-available systems.

For both techniques, the optical instrumentation was fixed to a set of orthogonal stages to provide traversing ability in either one or three-dimensions (depending on technique) in order to map out the accessible region-of-interest within the combustor. 


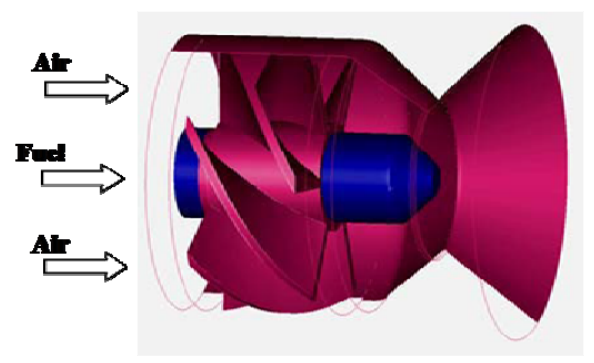

Figure 2.-Schematic drawing that shows the relative spatial positioning of the air swirler, fuel nozzle, and venturi for each injector element.

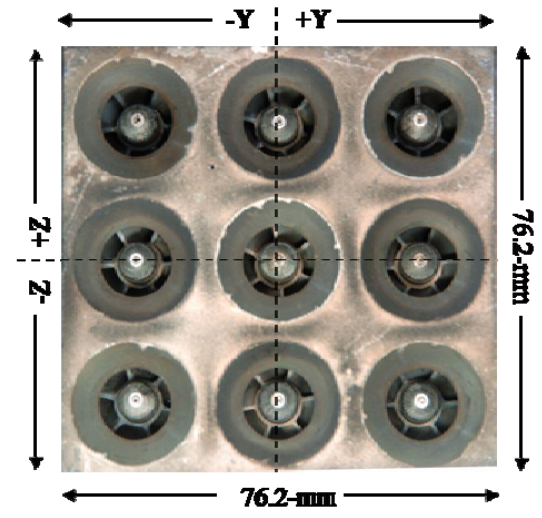

Figure 3.-End view of the 9-point LDI test hardware.

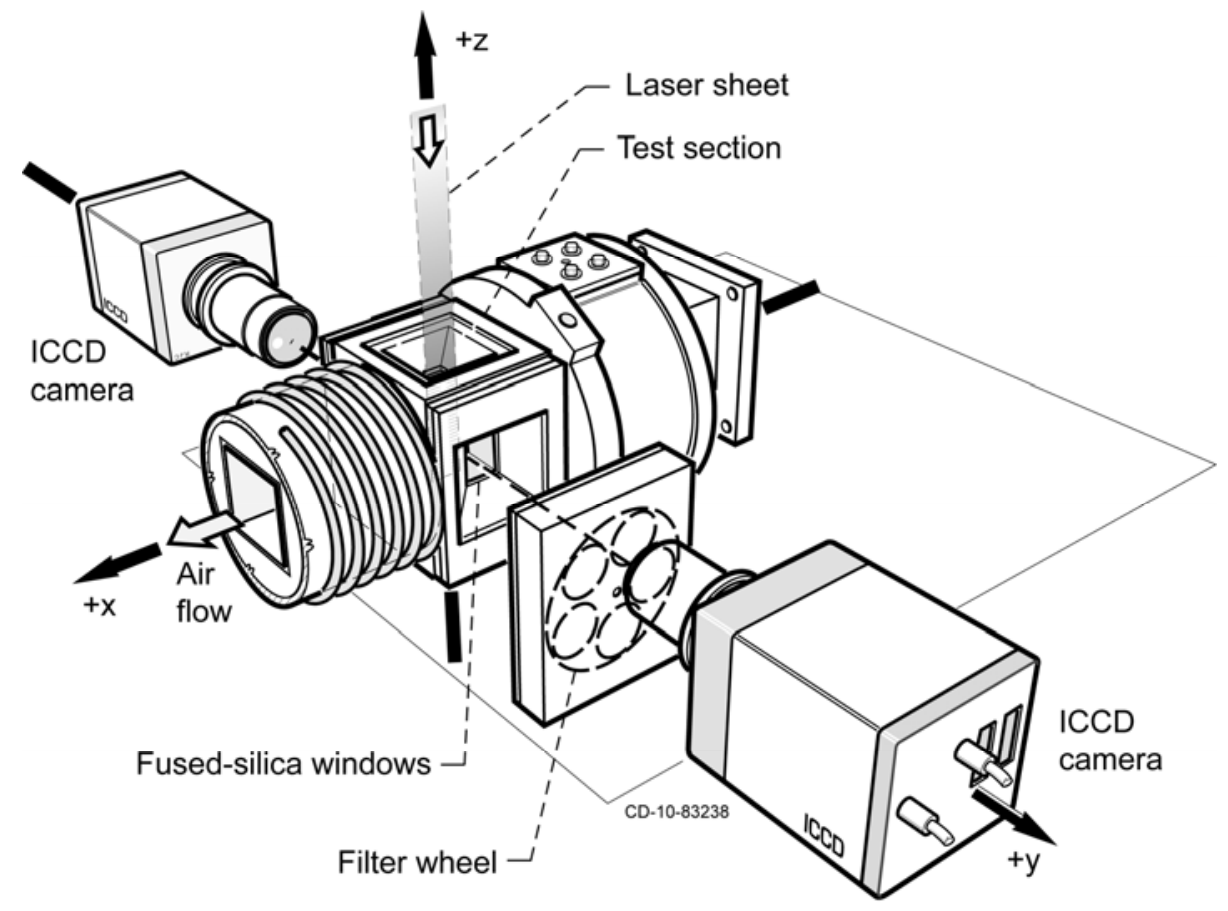

Figure 4.- Illustration that shows a typical planar imaging arrangement such as for two-dimensional PIV.

In this work $\mathrm{X}$ - is defined to be the stream-wise direction, with $X=0$-mm being the exit (dump) plane of the 9-point LDI hardware. Y- is the horizontal direction and $\mathrm{Z}$ - is the vertical direction, with $(\mathrm{Y}=0-\mathrm{mm}, \mathrm{Z}=0-\mathrm{mm})$ at the centerline of the center injector. Positive directions follow from the right-hand-rule, with positive $\mathrm{X}$ downstream and $\mathrm{Z}$ up.

\section{Particle Image Velocimetry}

The experimental setup for PIV was comparable to the Figure 4 illustration. PIV data were obtained using a dual head, frequency-doubled Nd:YAG laser operating at $15 \mathrm{~Hz}$.
The laser beams were expanded into sheets using a cylindrical lens and transmitted vertically into the combustor rig, with the sheet axis aligned with the flow direction. Images were acquired through a side window using the light scattered from fuel droplets to capture liquid phase velocity. We used an $\mathrm{f}=200-\mathrm{mm}, \mathrm{f} / 4$ lens to collect the light. This collection scheme imaged a region that spanned roughly $17-\mathrm{mm}$ axially by $23-\mathrm{mm}$ vertically, to isolate the center row of injectors. An interline transfer CCD camera captured the scattered light from adjacent laser pulses onto two individual frames. Because the second frame of standard interline transfer cameras has relatively long exposure times, the camera lens was 


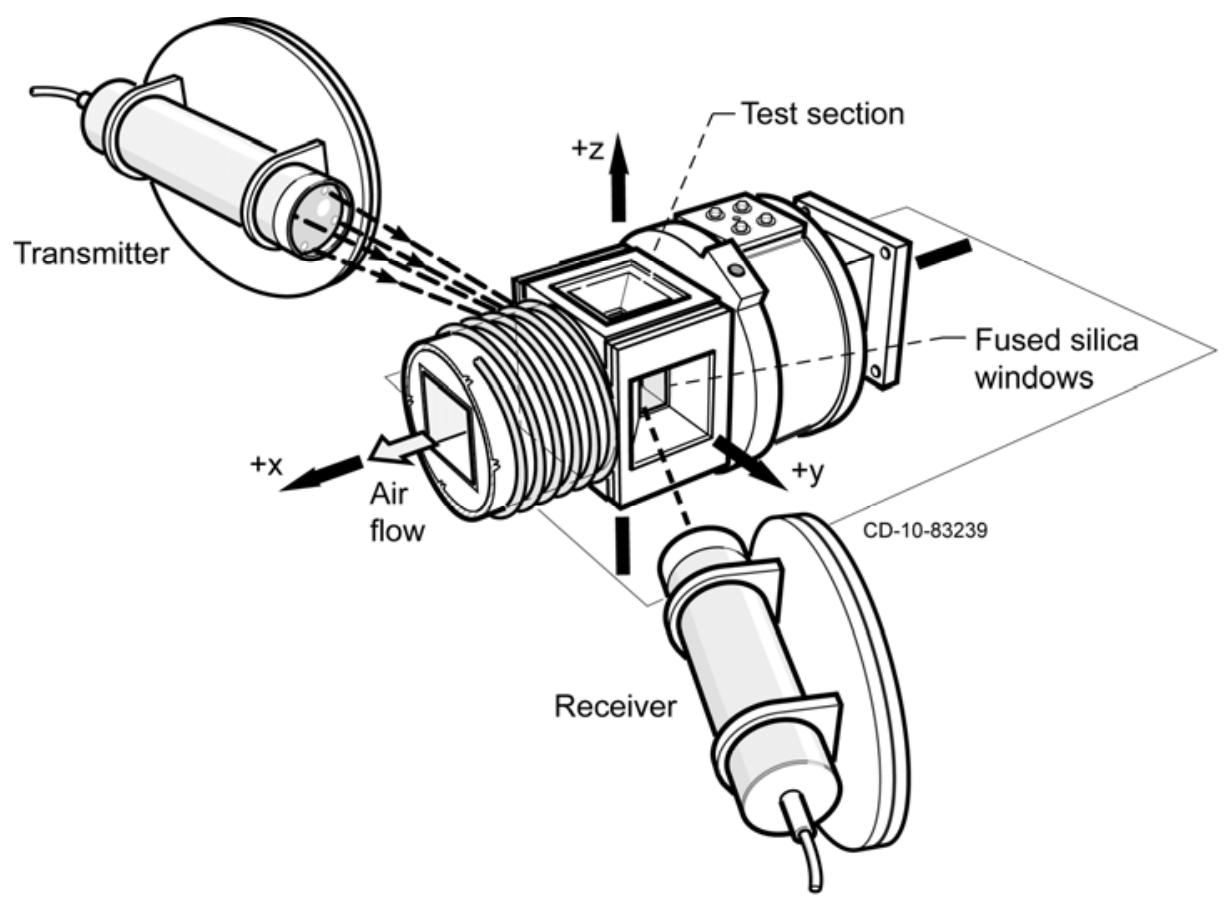

Figure 5.--Illustration that shows forward scatter arrangement for phase doppler interferometry in the upstream configuration.

outfitted with a mechanical leaf shutter capable of operating at 15-Hz. All synchronization was handled using a LaVision, Inc. programmable timing unit, PTU-8. Cross-correlation methods were then applied to create a displacement vector field for each image pair. LaVision's DaVis software version 7.2 was used to collect and process the images and produce axialvertical 2-D velocity fields. To map the optically-accessible volume, we traversed across the flow in the Y-direction in 1-mm increments.

\section{Phase Doppler Interferometry}

PDI was performed using a setup similar to that displayed in Figure 5 which employed transceiver and receiver optics in a $30^{\circ}$ off-axis forward scatter arrangement. Each transceiver beam was separately fine-adjusted to compensate for refraction through the combustor window and ensure that all beams overlapped within the rig.

PDI measurements were obtained using a three-component fiber-based system consisting of a 112-mm diameter FiberFlow probe (Model 5402-01), BSAFlow software and processing unit developed by Dantec Dynamics. An argonion laser was used to generate the green $(514.5-\mathrm{nm})$, blue (488-nm) and violet (476.5-nm) beam pairs for the transceiver. Due to limited optical access, the 3-color PDI system used a single optical head to transmit three beam pairs that intersected at the measurement volume. As shown in Figure 6(a), the beams did not provide orthogonal measurements, so a combined optical and geometric transform of the three measured velocity channels into the rectilinear coordinate system was required. Also, since this transformation was manually calculated and applied, we do not present RMS measurements for the channels; rather we calculate and report the local turbulence intensities, which can be obtained from the raw mean and RMS values.

Data were obtained in a point-wise manner using two different optical configurations to more fully access the flowfield. These arrangements and the combustor regions accessed are shown in Figure 6(b). Focal lenses for the transceiver and receiver were $310-\mathrm{mm}$ or $500-\mathrm{mm}$ depending on optical access and probe orientation. The $310-\mathrm{mm}$ focal length lens produced a measurement volume of $0.047-\mathrm{mm}$ in diameter by $0.4-\mathrm{mm}$ in length while the dimensions increased to $0.076-\mathrm{mm}$ in diameter by $1.03-\mathrm{mm}$ in length for the 500 -mm focal length lens.

For the upstream setup, the transmitter and receiver were angled upstream with their optic axes in a horizontal plane ( $\mathrm{Z}$ = constant) (see Fig. 5). This allowed us to probe the region immediately downstream of the center injector element, from the dump plane to approximately $\mathrm{X}=10-\mathrm{mm}$.

The downstream setup was similar to Figure 5, but with the transmitter and receiver angled downward. Their optical axes were in a vertical plane ( $\mathrm{X}=$ constant). This permitted access to the lower central region of the combustor, from approximately $\mathrm{X}=9-\mathrm{mm}$ to $15-\mathrm{mm}$. 


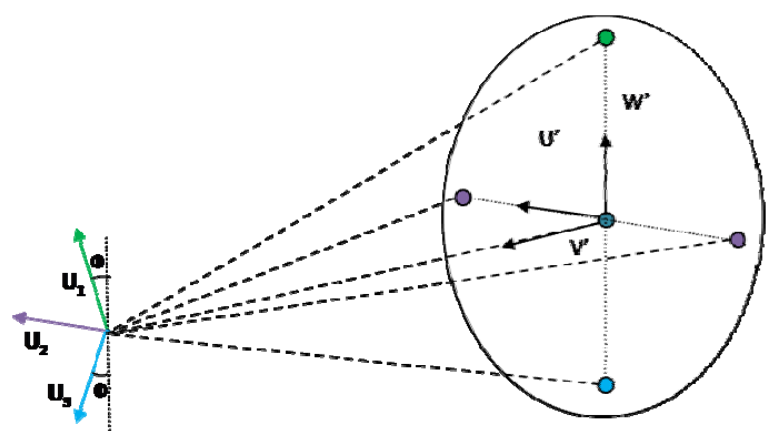

(a) Probe details.
Optic axis angles down $15^{\circ}$ relative

to horizontal for downstream setup

Optic axis angles upstream $15^{\circ}$ relative to flow direction for upstream setup

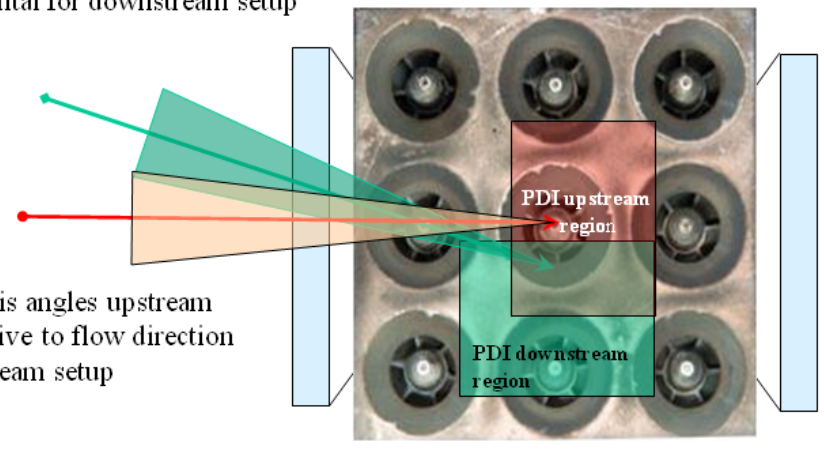

(b) Approximate combustor regions probed.

Figure 6.-PDI setup showing (a) arrangement of beams transmitted through the transceiver and their spatial relation to orthogonal components; (b) illustration that highlights the PDI beam insertion orientations and regions probed for the upstream (orange) and downstream (green) setups.

\section{Results and Discussion}

All data were collected during combustion, with calculated adiabatic flame temperatures between 1700 to $1833 \mathrm{~K}$. Five inlet conditions were considered, including high $(\mathrm{H})$, medium (M) and low (L) inlet temperatures and two pressures, designated (1) and (2). Table 1 provides the combustor test matrix including air flow rates and equivalence ratios. For all points, the air inlet pressure drop was 4 percent. The last three columns indicate the diagnostic techniques that were used to characterize operation at each condition. For the work presented, each diagnostic technique was used on a different test day and no techniques were performed simultaneously.

All experimental data have been processed and are presented in formats that attempt to thoroughly describe the fluid behavior of each test point in a clear, visual manner. Data are presented as either scatter plots, 1-D line plots or 2-D field plots. Two-dimensional plots are either side view plots at the $\mathrm{Y}=0$ plane with the downstream flow direction left to right, or end view plots $(\mathrm{X}=$ constant $)$ with downstream flow out of the page.

The results presented reflect an analysis of the liquid fuel spray without regard for the atomizing air. To provide some insight into the air flow structure in the absence of fuel, Figure 7 depicts a computational result that shows the predicted air flow features present downstream of the 9-point LDI (Ref. 6). The key feature to point out is the air-swirlinduced recirculation zone which forms immediately downstream of each injector element. Recirculation zones are necessary to support and stabilize the flame(s) in aircraft combustors. Figure 7 also shows the zero-velocity contours within which these recirculation zones exist. Given this inherent structure, we will expect to see reverse flow of the fuel droplets within this region. The expected reverse flow was confirmed with our PIV measurements (Ref. 7).

In other related work with a single LDI, Cai et al. (Ref. 8) studied both reacting and non-reacting cases at ambient
TABLE 1.-INLET CONDITION TEST MATRIX

\begin{tabular}{|c|c|c|c|c|c|c|}
\hline $\begin{array}{c}\text { Test } \\
\text { point }\end{array}$ & $\begin{array}{c}\mathrm{T}_{\text {in }} \\
(\mathrm{K})\end{array}$ & $\begin{array}{c}\mathrm{P}_{\text {in }} \\
(\mathrm{kPa})\end{array}$ & $\begin{array}{c}\mathrm{W}_{\text {air }} \\
(\mathrm{kg} / \mathrm{sec})\end{array}$ & $\Phi_{\mathrm{T}}$ & PIV & PDI \\
\hline H1 & 828 & 1034 & 0.45 & 0.41 & --- & $\mathrm{X}$ \\
\hline $\mathrm{H} 2$ & 828 & 1379 & 0.61 & 0.45 & --- & $\mathrm{X}$ \\
\hline M1 & 728 & 1034 & 0.50 & 0.45 & $\mathrm{X}$ & $\mathrm{X}$ \\
\hline M2 & 728 & 1379 & 0.68 & 0.45 & --- & $\mathrm{X}$ \\
\hline L1 & 672 & 1034 & 0.52 & 0.45 & --- & $\mathrm{X}$ \\
\hline
\end{tabular}

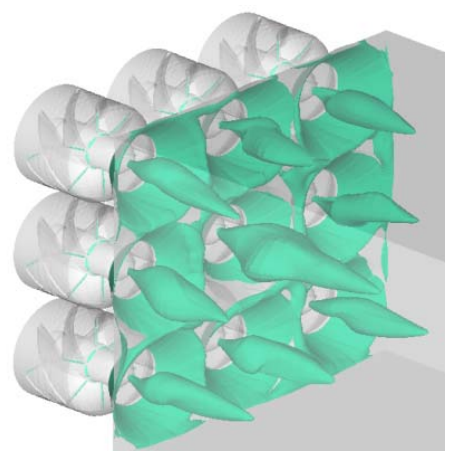

Figure 7.-Air-only computational result showing the zero-velocity isocontours of the 9-point LDI hardware (from Ref. 6).

temperature ( $\sim 298 \mathrm{~K})$ and pressure. Using PDI, they found that strong swirl affects mean diameter profiles, providing more uniform sizes and that heat released during combustion increases the mean and turbulent velocities relative to the nonreacting case. They concluded that the interaction between liquid and gas phases caused a decrease in the recirculation zone during combustion. The single LDI used in the Cai work has the same physical geometry as each element in the 9-point configuration used in this work, so Cai provides a useful 
comparison. However, the work by Cai used a square combustion chamber measuring 38-mm per side. To be exactly comparable with our work, the chamber should be 25 -mm per side.

To date, there is no study that compares the single element with this baseline 9-point LDI that duplicates both inlet and boundary conditions.

\section{Gross Features (PDI)}

Figure 8 contains side views within the vertical center plane of the mean axial and vertical velocities (vectors) and the local turbulence intensity contours immediately downstream of the center injector for the 728 and $828 \mathrm{~K}$ inlet conditions. Local turbulence intensity was calculated using the ratio of the RMS of the turbulent velocity fluctuations to the local Reynolds averaged mean velocity. Streamlines were added to the plots at $\pm 1 / 2$ of the diffuser exit radius to represent the outer boundaries of the hollow cone spray. We assumed and verified by measurement count number that the average bulk mass of fuel spray traveled through the paths swept out by the streamlines. The streamlines were then used to estimate spray angle for the center injector at each test condition. More accurate spray angle measurements could be made if the average radial distance to the centroid of the injected cone spray was precisely known. All images in Figure 8 show similar trends: (1) a spray angle roughly $80^{\circ}$ full cone with greater tangential velocity near the dump plane, which suggests the main flow from the nozzle is a hollow cone spray; (2) the region near the injector centerline (within the cone) has lower velocity; (3) the highest axial velocities occur at or near the region where the flow from the upper and lower injectors mix with that of the center injector. The region where the jets mix is also the area of highest turbulence intensity. The second highest levels of turbulence occur near the injector centerline, within the first few millimeters from the dump plane. The lowest levels of turbulence occur around the boundaries of the spray cone.

Figure 9 shows PDI results obtained at point M1, which plots in the top row the $\mathrm{V}-\mathrm{W}$ vectors and U-contours for $\mathrm{X}=0-\mathrm{mm}$ (left), 3-mm (center), and 6-mm (right column). The bottom row shows the turbulence intensity contours along with the droplet count (scatter plot) that corresponds with each axial position. The circles represent the projected diffuser exit diameters at the dump plane.

From the axial velocity contours, one can visualize the region of core recirculation, whose average fuel drop velocity is positive. The $\mathrm{V}-\mathrm{W}$ vectors reflect the tangential swirl imparted to the fuel from both the fuel nozzle and the swirling air. The turbulence contours from these perspective views highlight the higher turbulence intensity along the centerline at the injector exit plane and show that levels dissipate from that central core as the flow progresses downstream. The scatter plot represents the number of drops measured at each location.

Figure 10(a) shows a representative contour of the mean $\mathrm{V}$ velocity. Figure 10(b) shows a representative contour of the mean $\mathrm{W}$ velocity. The $\mathrm{Z}-\mathrm{Y}$ plots show results from inlet condition M1, the Z-X plots show M2 results. Given our limited optical access, these plots are useful to highlight the symmetrical flow patterns from the 9-point LDI hardware.

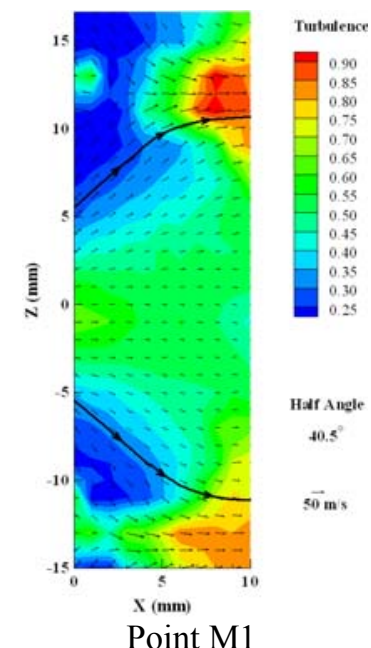

Point M1
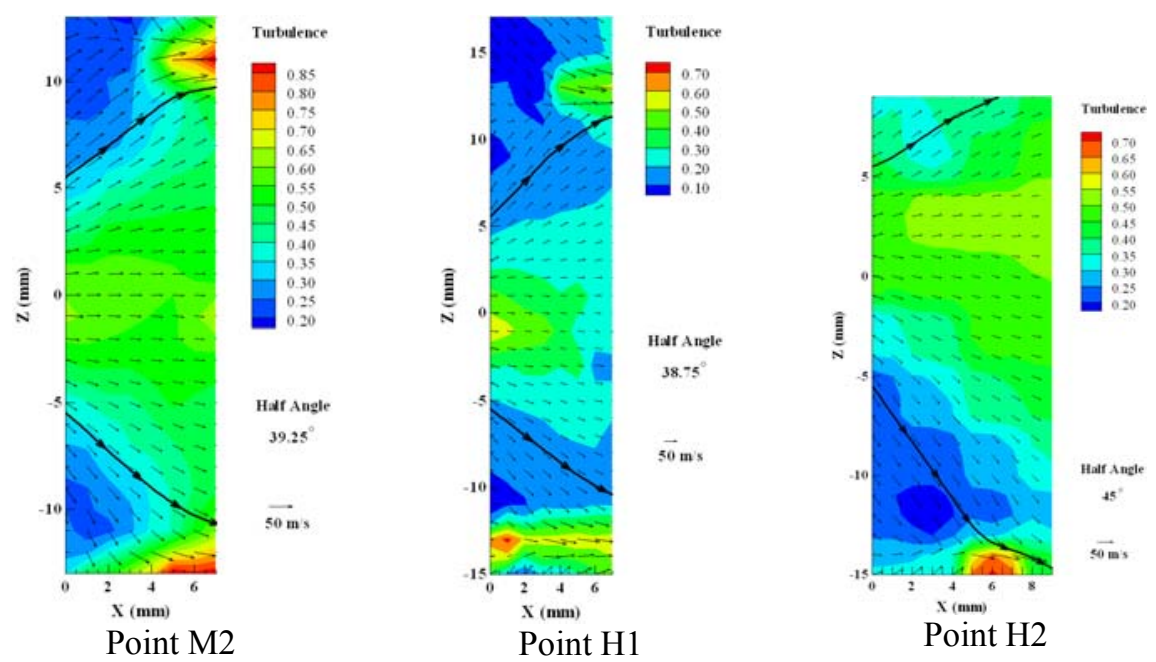

Figure 8.-Side views at $y=0$ that show the average $U-W$ fuel velocity vectors and local turbulence intensity contours for the medium and high inlet temperature conditions. Flow is left to right. 

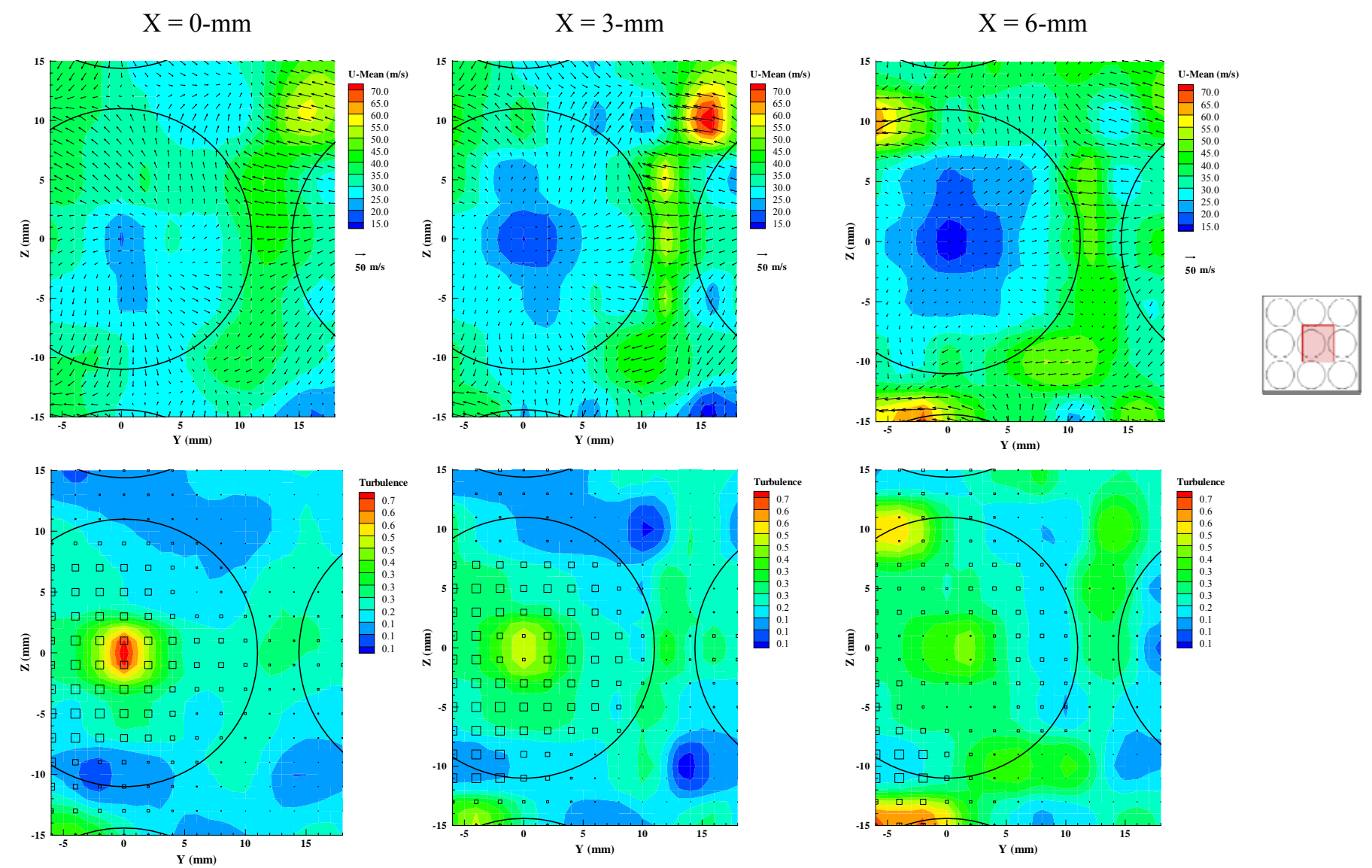

Figure 9.-Results from inlet condition $\mathrm{M} 1$ at $\mathrm{X}=0,3$, and 6-mm from injector dump plane. Top row: 3-D velocity field with axial velocities represented by contour. Bottom row: Turbulence intensity contours and scatter plot representing number of drops measured. Positive $\mathrm{X}$ flow direction is out of the page.

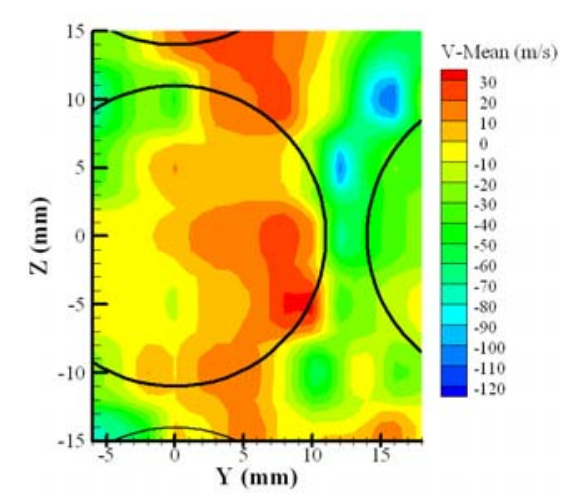

(a)

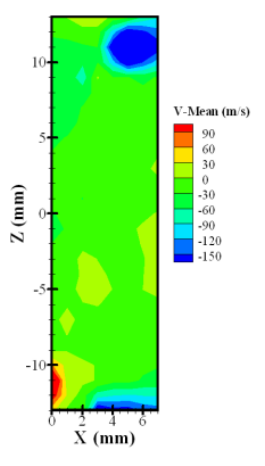

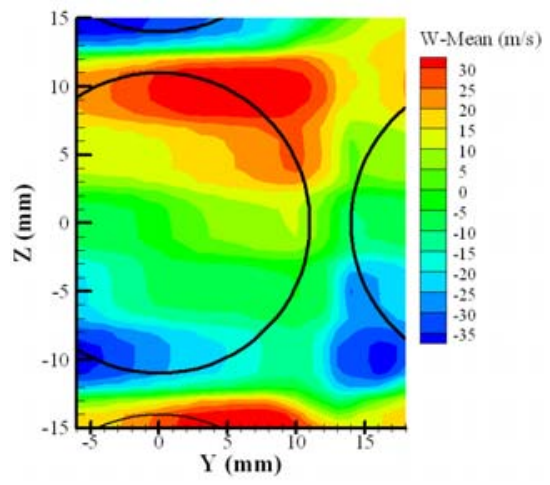

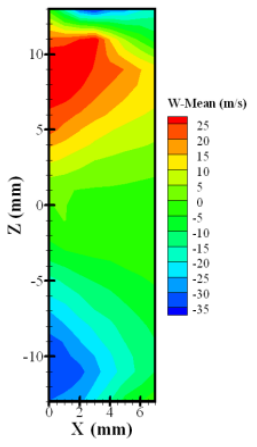

(b)

Figure 10.-Examples that highlight symmetry. (a) Contour plot of mean $V$ components from PDI measurements. (b) Contour plot of mean W components from PDI measurements. The Z-Y plots show end views (flow out of page) at the $X=3-\mathrm{mm}$ plane at inlet condition M1. The $Z-X$ plots show the side view at $Y=0$, with flow from left to right, at inlet condition M2. 


\section{Drop Size Differentiated Flows (PDI)}

Figures 11 through 15 show results when considering fuel drop size. Because the average drop size range was small, we have three size bins. These three $\mathrm{D}_{10}$ size ranges are: $\mathrm{D}_{10}$ smaller than $10-\mu \mathrm{m}$, between $10-$ to $20-\mu \mathrm{m}$ and greater than $20-\mu \mathrm{m}$.

Figure 11 shows the mean axial velocity at inlet condition M1 for the three drop size ranges along a vertical rake within the $\mathrm{Y}=0-\mathrm{mm}$ plane immediately downstream of the center injector. As expected, the largest drops are typically the slowest, and the smallest drops move fastest. Only the drops larger than $10-\mu \mathrm{m}$ have negative average axial velocity, observed at the 3-mm downstream location, though all drops immediately downstream have relatively low axial velocity. The highest velocities occur in the region between adjacent injectors, around $Z \pm 12-\mathrm{mm}$. By $X=9$-mm, only small drops remain.

Figure 12 presents $\mathrm{V}-\mathrm{W}$ vectors resultant from the $\mathrm{H} 2$ inlet condition at $X=3-\mathrm{mm}$. From this perspective, one can see that the center of rotation is near the centerline, which has little to no V-W velocity. The V-W components increase with greater distance from the centerline, predominately radially outward. The tangential influence of the incoming swirling air is evident in that we begin to see separation in the direction the drops move, depending on their size. Although the different directions the drops take become distinguishable, there is no obvious pattern that would allow us to say that any one size class moves in a particular manner.

Distributions of the axial velocity component versus linear droplet diameter, $\mathrm{D}_{10}$, for the 728 and $828 \mathrm{~K}$ cases are displayed in Figure 13. Data contained in these images have been processed to remove outlier drops with unusually high velocity components well beyond average. In all cases, the region probed was within the vertical $\mathrm{Y}=0$ - $\mathrm{mm}$ plane immediately downstream of the center injector, from the $Z=0-\mathrm{mm}$ position to below the centerline at $Z=-15-\mathrm{mm}$. Low counts at the $X=0-\mathrm{mm}$ plane are attributed to high optical thickness at the direct exit of the injection system.

The fuel injector pressure drop for the low combustor pressure cases (left column) is approximately $172 \mathrm{kPa}$ (25 psid) below that of the higher pressure cases (right column). For each set, a similar trend may be noted. Plots for all test conditions show a general decrease in fuel drop size and count with downstream progression as fuel particles are being consumed by chemical reaction and vaporization processes.

The high inlet temperature conditions present smaller fuel drops on average, compared to the lower inlet temperature cases. These drops also vaporize more rapidly, as no drops are observed at the $X=9-\mathrm{mm}$ location. Also, the higher temperature condition shows that a greater percentage of the drops measured have positive axial velocity. As inlet temperature increases, the fraction of drops that have negative axial velocity decreases. This suggests the strength of the recirculation zone decreases with higher inlet temperature.

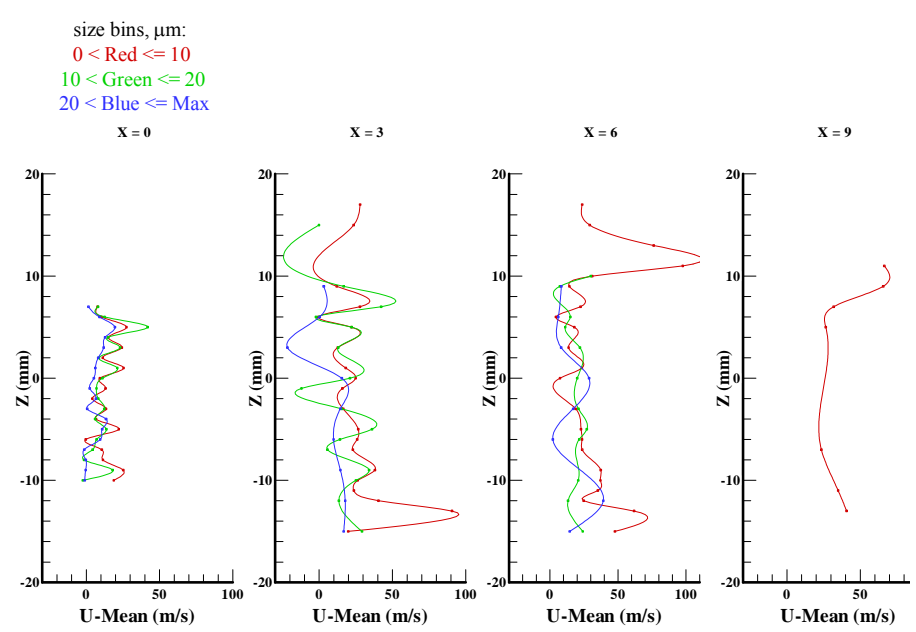

Figure 11.-Axial velocity profiles along $Y=0$ for three drop size ranges, at $\mathrm{X}=0-$, 3-, 6-, and 9-mm. Inlet condition $\mathrm{M} 1$.

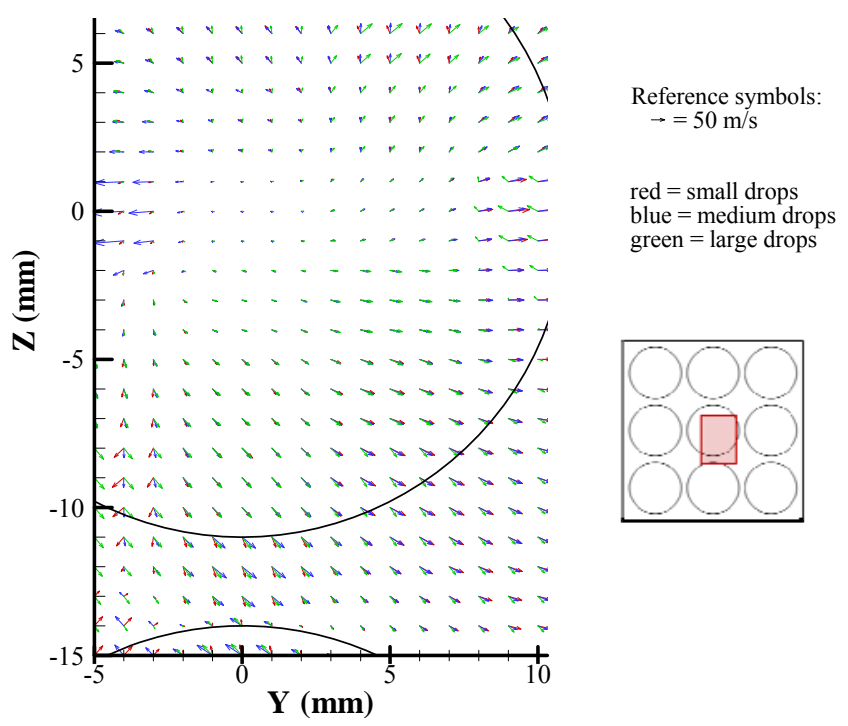

Figure 12.-Velocity vectors for three drop size bins at the $X=3-\mathrm{mm}$ plane. Size bins: small drops $<10 \mu \mathrm{m}$; medium, 10 to $20 \mu \mathrm{m}$; large $>20 \mu \mathrm{m}$. Inlet condition H2. Flow out of page.

A greater degree of atomization is expected with increased fuel injector pressure drop, and the bottom row results serve to demonstrate this behavior. Despite the higher pressure case flowing $0.0057-\mathrm{kg} / \mathrm{s}\left(0.0128-\mathrm{lb}_{\mathrm{m}} / \mathrm{s}\right)$ more fuel, the number of drops measured is lower by more than an order of magnitude, and at each axial position, the average drop diameter decreases. The reason this effect is not apparent for the high inlet temperature cases is because the fuel-to-air ratios are not equivalent. Condition $\mathrm{H} 1$ had $\phi=0.41$ instead of 0.45 , and disproportionately less fuel than its high pressure counterpart, for a difference of 0.0053 rather than $0.0049 \mathrm{~kg} / \mathrm{s}$. Another factor is that the fuel more readily vaporizes at this higher inlet 

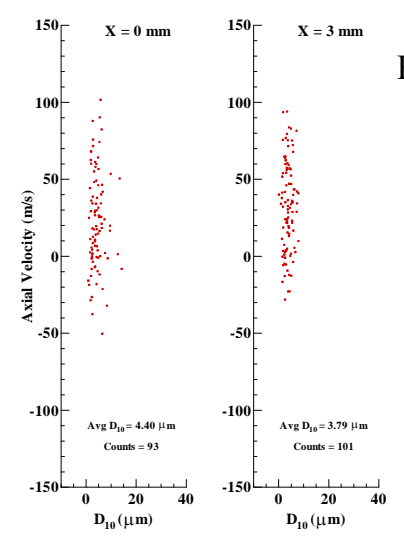

$\mathrm{H} 1$
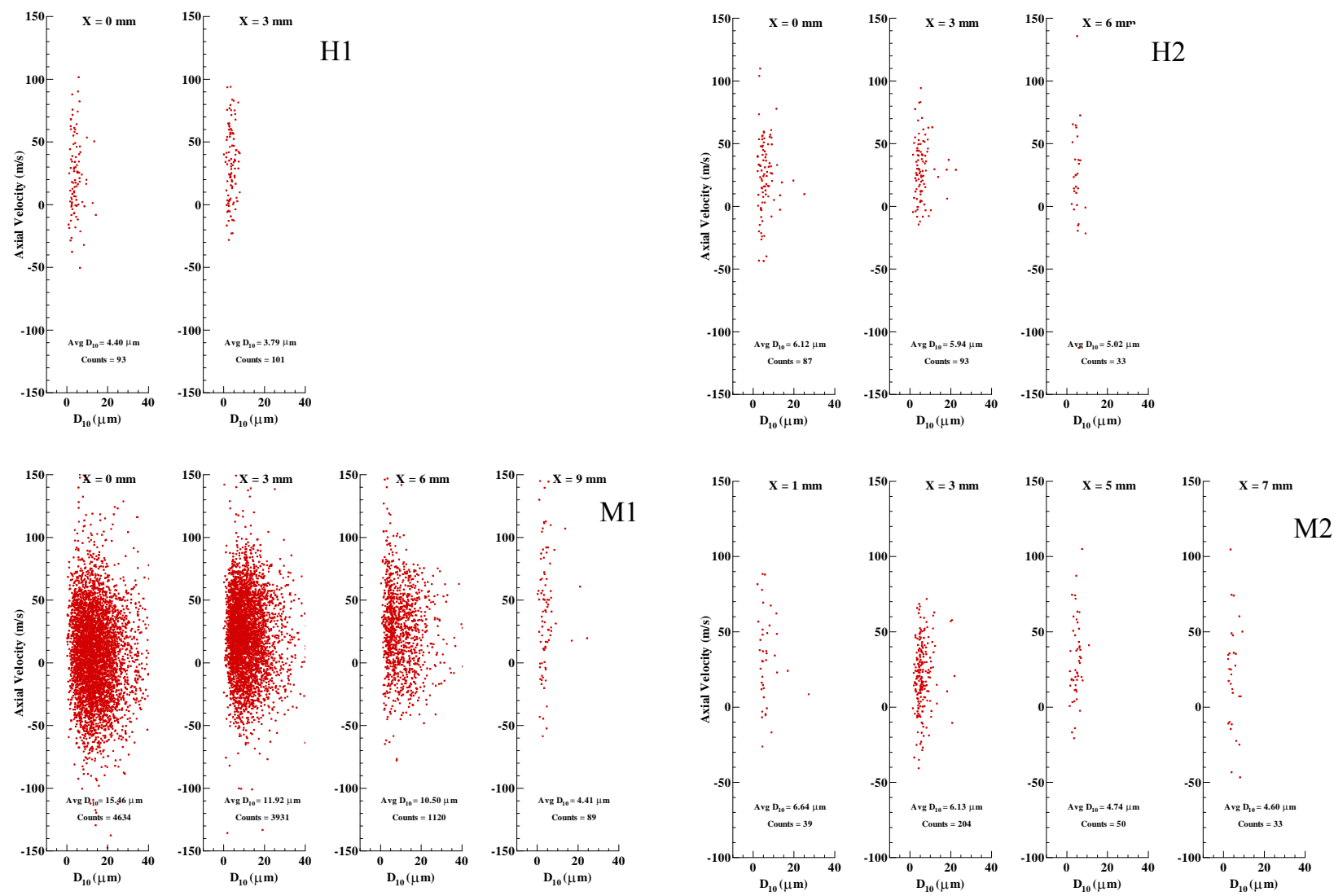

Figure 13.-Distribution of droplet mean diameter D10, with axial velocity for the high and medium inlet temperature conditions. Drops are located in the immediate downstream region of the center injector, within the $\mathrm{Y}=0$ plane, for various axial distances from dump plane.
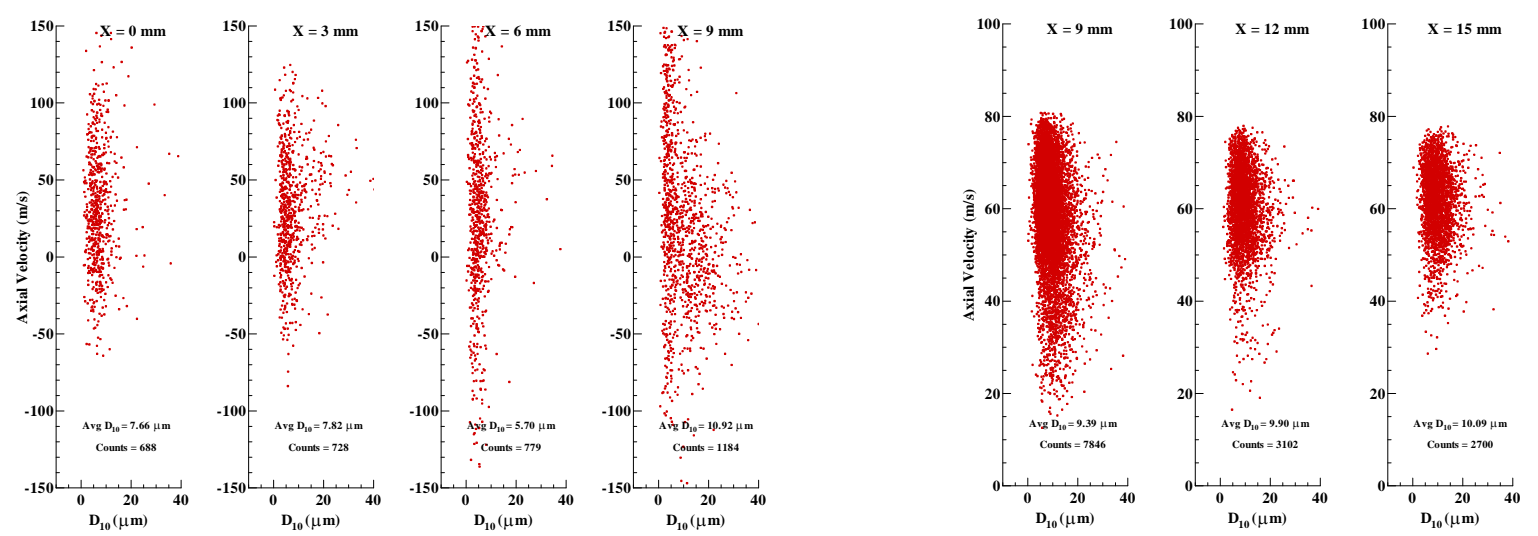

Figure 14.-Distribution of droplet mean diameter D10, with axial velocity, at various axial locations within the $\mathrm{Y}=0$ plane at inlet condition L1. Drops are located in the immediate downstream region of the center injector (left), or downstream of the lower injector (right).

temperature. Despite these factors, the number of drops measured at conditions $\mathrm{H} 1$ and $\mathrm{H} 2$ is comparable, and supports the expectation that the larger fuel pressure drop enhances atomization.

The drop size-velocity distribution for the lowest inlet temperature case, L1, is shown in Figure 14 for the upstream (left) and downstream configurations. We would expect to see both a higher number of droplets measured and larger drops at the upstream location, but instead record many fewer drops than at condition M1. The drops also are smaller. These discrepancies from expectation we attribute to the optical thickness and/or large density gradients of the flow field at this inlet condition that helped to obscure the signal. 
At the downstream location, the drops measured are primarily from the upper half of the lower injector, though there is probably contribution from the lower half of the middle injector, as well. This location should correspond with an area downstream of the recirculation zone, where there may be interaction between adjacent injectors. Many more droplets were measured at this downstream location, all with positive velocity.

The contour plots in Figure 15 display the influence of drop diameter on axial velocities at the downstream locations of X $=9-, 12-$, and 15-mm. Data represent the L1 case. For these positions, only two size bins are used. The top row contains the average axial velocities for drops with linear diameters between 0 - and $10-\mu \mathrm{m}$, non-inclusive. The bottom row portrays the same information for drop sizes in the range of $10-$ to $20-\mu \mathrm{m}$, inclusive. For each size range, the span of axial velocities decreases with downstream progression, indicating the flow is approaching a steady, uniform distribution. By comparing velocity spans of the top and bottom rows, it appears evident that the small drops more closely track the actual airflow characteristics during combustion.

\section{PIV Results}

Figures 16 and 17 present PIV results. The field of view used for PIV isolates the center row of injectors. The presented fields are the average of only 250 image pairs, and are not necessarily a good statistical sampling. However, limiting the number of pairs was convenient for this first attempt at PIV in a combusting case, allowing us to consider issues of timing, using a shutter, and data storage. Figure 16 shows the resultant average droplet velocity and RMS fields from PIV for inlet condition $\mathrm{M} 1$ at the $\mathrm{Y}=0$-mm position. For comparison, the PDI average velocity data from the same region is plotted on the same scale. The range in RMS for PIV is similar to what we encountered for the individual PDI channels. Using the PIV vector plot (center image) we measured a full spray angle of approximately $80^{\circ}$, which is consistent with the PDI results.

Taking into account the relatively small PIV sample size, the PIV and PDI results compare well and show similar trends. One key difference between the PIV and PDI vector fields is in the core central region, where the PIV appears
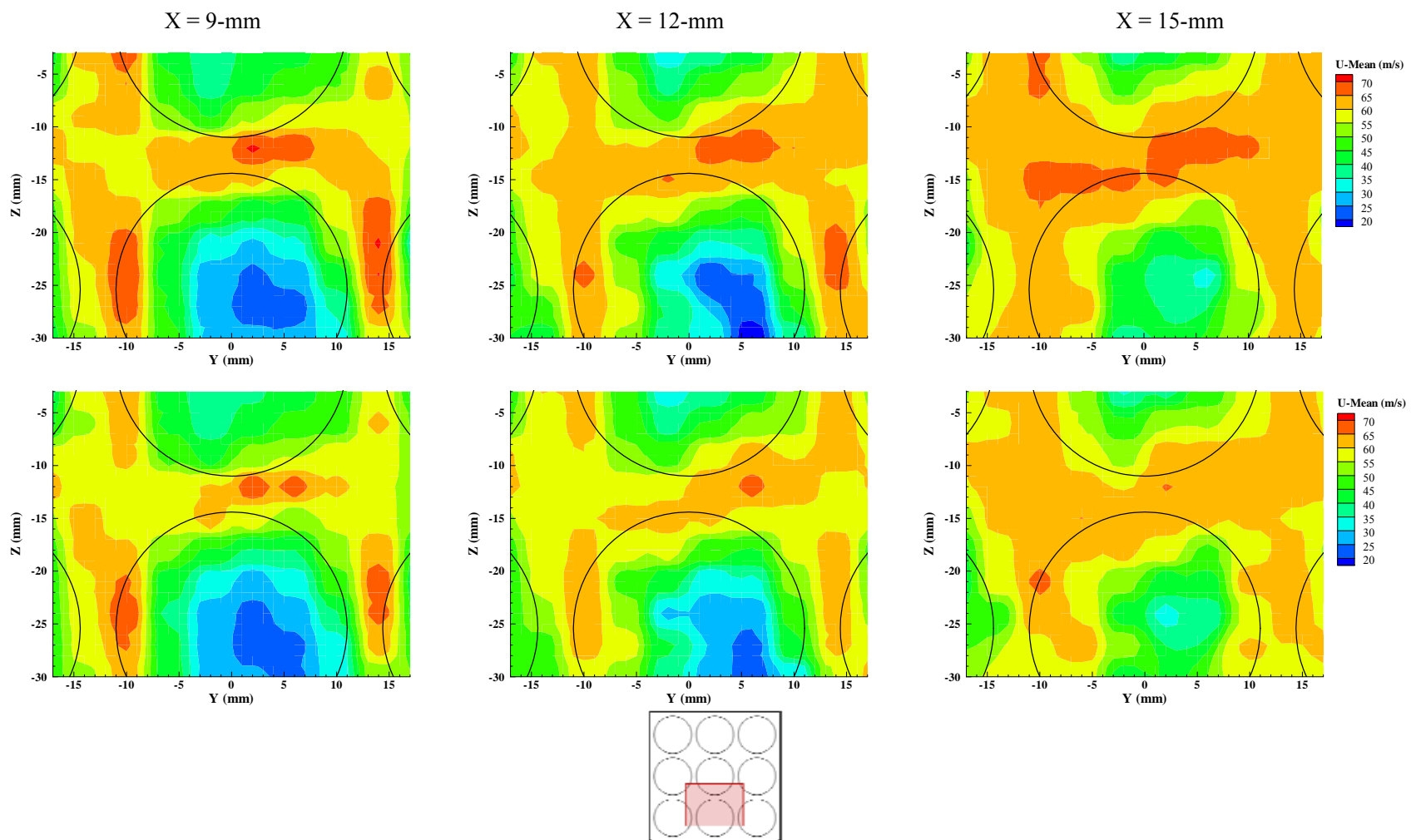

Figure 15.-Results from point L1 at $X=9,12$, and 15-mm from injector exit. Top row: average axial velocities represented by contour for droplets between 0 and 10- $\mu \mathrm{m}$. Bottom row: average axial velocities represented by contour for droplets between 10 and $20-\mu \mathrm{m}$. Flow direction is out of the page. 

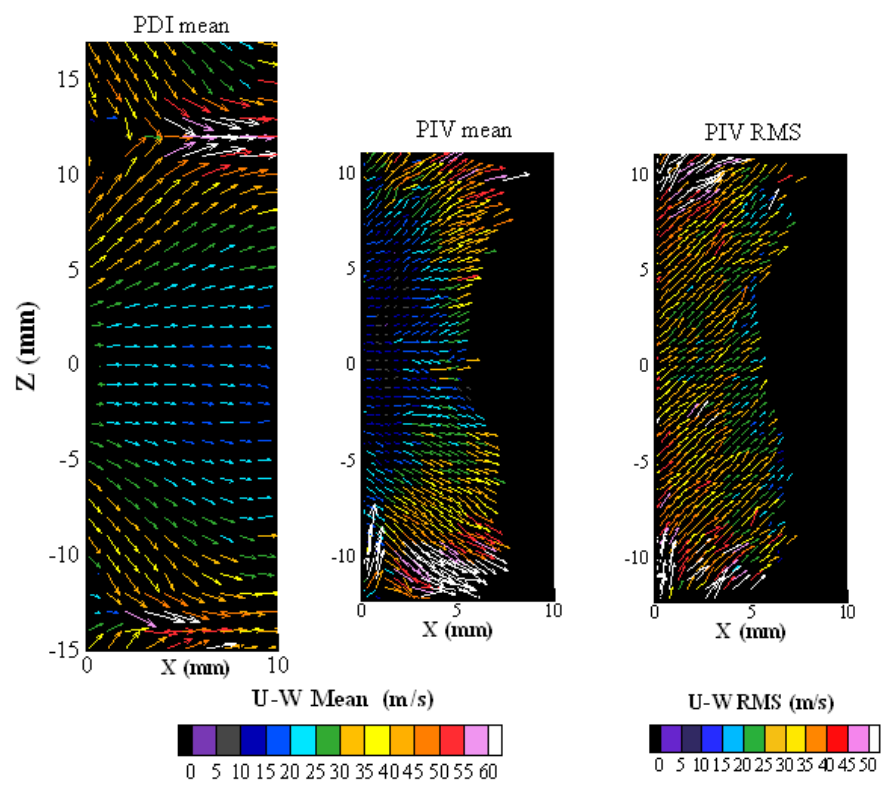

Figure 16.-Results from PDI (left) and PIV (center and right columns) at $\mathrm{Y}=0$-mm for inlet condition M1.

sparse. One key advantage of PDI for droplet velocity measurement is that the $30^{\circ}$ off-axis forward scattering angle is optimal for Mie scattering, whereas the $90^{\circ}$ scattering angle used for PIV and other planar imaging techniques is less efficient. On the other hand, because PIV is a whole-field technique, we obtain 2-D snapshots of droplet and velocity that would require much more time-and multiple optical arrangements - to acquire using PDI.

Another issue this comparison serves to highlight is the optical density problem, mentioned earlier with respect to the point L1 PDI data. Figure 17 shows a series of X-plane slices from the data block we derived by combining results of all 47 $\mathrm{U}-\mathrm{W}$ vector fields. In looking at these end views we see an obvious difference between the spray pattern on the camera's near-side $(Y \geq 0)$ and the opposite side of the flow field. Although the distance from the camera to the probe region was fixed, the light scattered had to travel through more fluid as the distance from the camera increased. Additionally, Mie scatter intensity goes as the square of drop size surface area, so the signal from the smallest drops may be more obscured than from larger drops. Field thickness, obscuration, and multiple scattering effects contribute to degrade the initial images and the final processed result.

Nevertheless, this whole field approach of PIV allows us to conclude the presence of symmetry in the flow field structure, as well as highlight the injector spray pattern using a greater field of view than that attainable through PDI. The images in Figure 17 tell us that the adjacent fuel sprays begin mixing by $X=3-\mathrm{mm}$ and are fully involved by $5-\mathrm{mm}$. The farthest extent of the spray (most drops have vaporized) we found to be around $11-\mathrm{mm}$ at this inlet condition, which is consistent with the range we found using PDI.
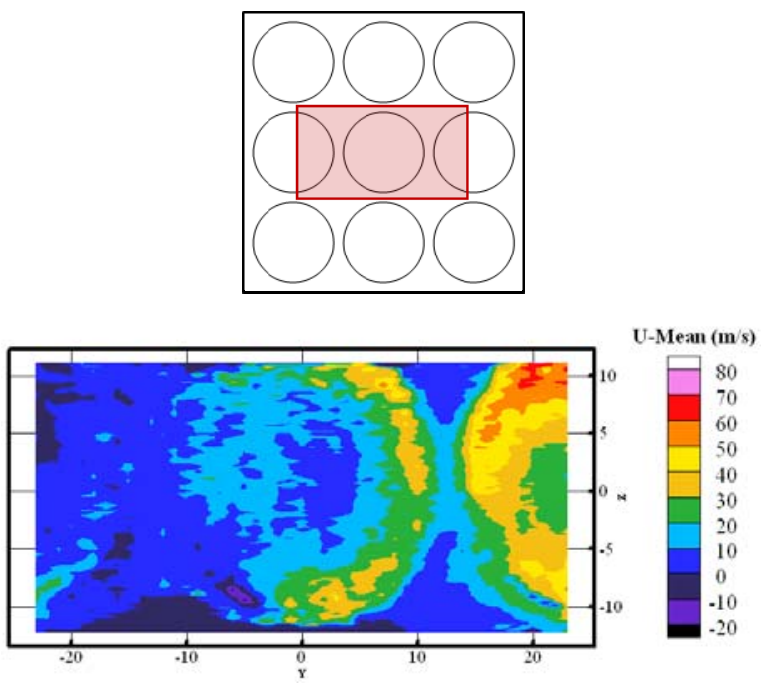

$$
\mathrm{X} \cong 1-\mathrm{mm}
$$

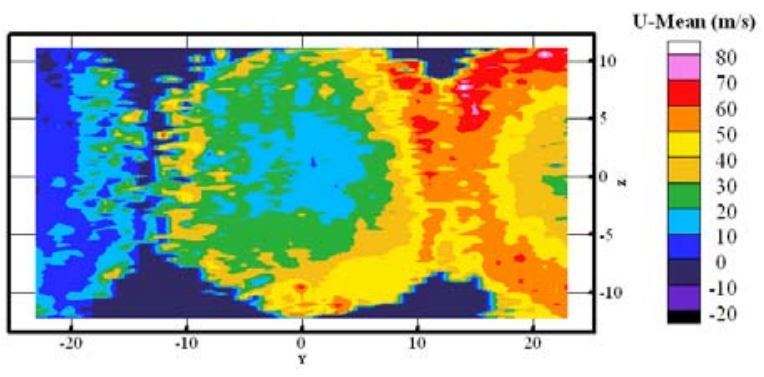

$\mathrm{X} \cong 2.5-\mathrm{mm}$

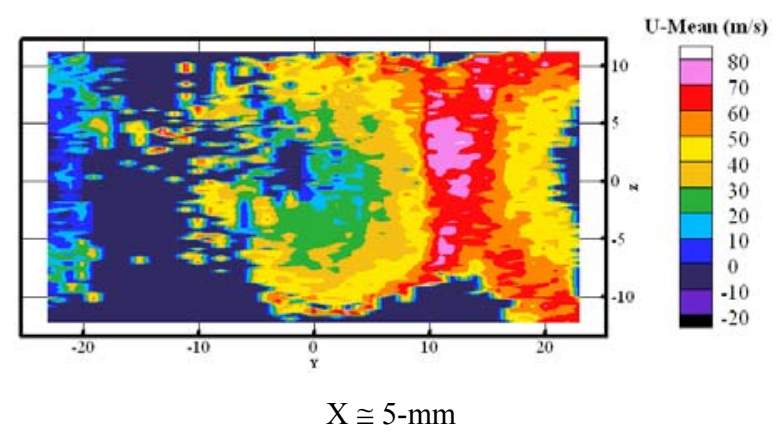

Figure 17.-Axial velocity contours at selected axial planes obtained via PIV, inlet condition M1. Flow out of page.

\section{Summary}

To aid in the process of building the next generation of aircraft powerplants that will meet the increasingly stringent restrictions on emissions, researchers at the NASA Glenn Research Center have been investigating a novel 9-point lean direct injector. In order to meet the challenges involved in taking this injector from test lab to commercial aircraft engine, a more thorough understanding of the chemical as well as physical processes occurring within the flowfield of 
this injector is required. Recent advances in optical diagnostic methods offer the greatest opportunity to provide this information. Given our facility and its available optical access, PDI and PIV were chosen as complementary candidate techniques to fully describe parametrically the flowfield of this injector.

Our results demonstrate that PDI was successful at locating the core recirculation zones and at determining the injector full cone spray angle which was found to be roughly $80^{\circ}$ in each case. PDI was also particularly useful in ascertaining droplet size, local turbulence levels and velocity vector components. Average droplet diameters, $\mathrm{D}_{10}$, were typically less than $20-\mu \mathrm{m}$. Mapping the droplet horizontal and vertical velocity vectors showed the clock-wise circulation (in the stream-wise sense) that the $60^{\circ}$ air swirlers imparted to the flow. The droplet diameter data was also significant in showing that the 9-point LDI hardware is highly effective at atomizing the Jet-A fuel and showing that all but the largest droplets were completely vaporized within the first $15-\mathrm{mm}$ from the injector exit. PDI measurements revealed that the highest velocities occurred where the jets from adjacent injectors mix, while the lowest velocities were found within each injector's hollow fuel cone. Local turbulence levels were also shown to be at a maximum where adjacent fuel jets mixed and at a minimum in the boundary region of the spray cones. PIV results, like those of PDI, also revealed an $80^{\circ}$ full cone spray angle and yielded similar results for average droplet velocity and RMS fields. Both techniques were also found to be similarly affected by the optical thickness of the region being examined with the amount of data being reduced as the optical thickness at the measurement location increased.

Future work will include testing to better assess interactions between LDI elements. Plans include testing both seeded cold (unfueled) and combusting cases at the same air inlet conditions. Plans also include testing with fuel to the center element only without fuel to neighbors, which will enable us to more readily control boundary conditions so that we may directly compare single and multiple injector configurations.

\section{References}

1. Rizk, Nader K., 2004, "Fuel Atomization Effects on Combustor Performance," AIAA-2004-3540.

2. Penner, J., Lister, D., Griggs, D., Dokken, D., and McFarland, M., "Regulatory and Market-Based Mitigation Measures," Aviation and the Global Atmosphere: A Special Report of IPCC Working Groups, Cambridge University Press, Cambridge, UK, 1999, pp. 335-348.

3. Tacina, R., Wey, C, Laing, P., and Mansour, A., 2002, "Sector Tests of a Low-NOx, Lean Direct Injection, Multipoint Integrated Module Combustor Concept," ASME Paper No. GT-2002-30089.

4. Tacina, R., Lee, P., and Wey, C., 2005, “A Lean-DirectInjection Combustor Using a 9 Point Swirl-Venturi Fuel Injector," ISABE Paper No. ISABE-2005-1106.

5. Hicks, Y.R., Locke, R.J., Wey, C.C., and Bianco, J., 1993, "A Unique Optically Accessible Flame Tube for Lean Combustor Studies," NASA/TM-107073.

6. Davoudzadeh, F., Liu, N.-S., and Moder, J.P., 2006, "Investigations of Swirling Air Flows Generated by Axial Swirlers in a Flame Tube," ASME Paper No. GT-200691300.

7. Hicks, Y.R., Locke, R.J., and Anderson, R.C., 2007, “Optical Measurements in a Combustor Using a 9-Point SwirlVenturi Fuel Injector," ISABE Paper No. 2007-1280.

8. Cai, J., Jeng, S.-M., and Tacina, R., 2005, "The Structure of a Swirl-Stabilized Reacting Spray Issued From an Axial Swirler," AIAA-2005-1424. 


\begin{tabular}{|c|c|c|c|c|c|}
\hline \multicolumn{5}{|c|}{ REPORT DOCUMENTATION PAGE } & $\begin{array}{l}\text { Form Approved } \\
\text { OMB No. 0704-0188 }\end{array}$ \\
\hline \multicolumn{6}{|c|}{ 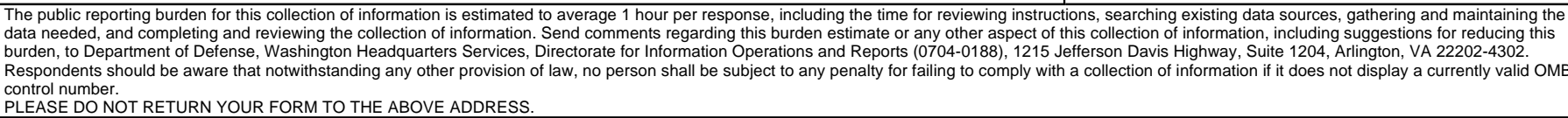 } \\
\hline \multicolumn{2}{|c|}{$\begin{array}{l}\text { 1. REPORT DATE (DD-MM-YYYY) } \\
01-10-2010\end{array}$} & \multicolumn{3}{|c|}{$\begin{array}{l}\text { 2. REPORT TYPE } \\
\text { Technical Memorandum }\end{array}$} & 3. DATES COVERED (From - To) \\
\hline \multirow{3}{*}{\multicolumn{5}{|c|}{$\begin{array}{l}\text { 4. TITLE AND SUBTITLE } \\
\text { Optical Characterization of a Multipoint Lean Direct Injector for Gas Turbine Combustors: } \\
\text { Velocity and Fuel Drop Size Measurements }\end{array}$}} & 5a. CONTRACT NUMBER \\
\hline & & & & & 5b. GRANT NUMBER \\
\hline & & & & & 5c. PROGRAM ELEMENT NUMBER \\
\hline \multirow{3}{*}{\multicolumn{5}{|c|}{$\begin{array}{l}\text { 6. AUTHOR(S) } \\
\text { Heath, Christopher, M.; Anderson, Robert, C.; Locke, Randy, J.; Hicks, Yolanda, R. }\end{array}$}} & 5d. PROJECT NUMBER \\
\hline & & & & & 5e. TASK NUMBER \\
\hline & & & & & $\begin{array}{l}\text { 5f. WORK UNIT NUMBER } \\
\text { WBS 561581.02.08.03.16.03 }\end{array}$ \\
\hline \multicolumn{5}{|c|}{$\begin{array}{l}\text { 7. PERFORMING ORGANIZATION NAME(S) AND ADDRESS(ES) } \\
\text { National Aeronautics and Space Administration } \\
\text { John H. Glenn Research Center at Lewis Field } \\
\text { Cleveland, Ohio 44135-3191 }\end{array}$} & $\begin{array}{l}\text { 8. PERFORMING ORGANIZATION } \\
\text { REPORT NUMBER } \\
\text { E-17301 }\end{array}$ \\
\hline \multirow{2}{*}{\multicolumn{5}{|c|}{$\begin{array}{l}\text { 9. SPONSORING/MONITORING AGENCY NAME(S) AND ADDRESS(ES) } \\
\text { National Aeronautics and Space Administration } \\
\text { Washington, DC 20546-0001 }\end{array}$}} & $\begin{array}{l}\text { 10. SPONSORING/MONITOR'S } \\
\text { ACRONYM(S) } \\
\text { NASA }\end{array}$ \\
\hline & & & & & $\begin{array}{l}\text { 11. SPONSORING/MONITORING } \\
\text { REPORT NUMBER } \\
\text { NASA/TM-2010-216365 }\end{array}$ \\
\hline \multicolumn{6}{|c|}{$\begin{array}{l}\text { 12. DISTRIBUTION/AVAILABILITY STATEMENT } \\
\text { Unclassified-Unlimited } \\
\text { Subject Categories: } 07,34 \text {, and } 35 \\
\text { Available electronically at http://gltrs.grc.nasa.gov } \\
\text { This publication is available from the NASA Center for AeroSpace Information, 443-757-5802 }\end{array}$} \\
\hline \multicolumn{6}{|c|}{ 13. SUPPLEMENTARY NOTES } \\
\hline \multicolumn{6}{|c|}{$\begin{array}{l}\text { 14. ABSTRACT } \\
\text { Performance of a multipoint, lean direct injection (MP-LDI) strategy for low emission aero-propulsion systems has been tested in a Jet-A } \\
\text { fueled, lean flame tube combustion rig. Operating conditions for the series of tests included inlet air temperatures between } 672 \text { and } 828 \mathrm{~K} \text {, } \\
\text { pressures between } 1034 \text { and } 1379 \mathrm{kPa} \text { and total equivalence ratios between } 0.41 \text { and } 0.45 \text {, resulting in equilibrium flame temperatures } \\
\text { approaching } 1800 \mathrm{~K} \text {. Ranges of operation were selected to represent the spectrum of subsonic and supersonic flight conditions projected for } \\
\text { the next-generation of commercial aircraft. This document reports laser-based measurements of in situ fuel velocities and fuel drop sizes for } \\
\text { the NASA 9-point LDI hardware arranged in a } 3 \times 3 \text { square grid configuration. Data obtained represent a region of the flame tube combustor } \\
\text { with optical access that extends } 38.1 \text {-mm downstream of the fuel injection site. All data were obtained within reacting flows, without } \\
\text { particle seeding. Two diagnostic methods were employed to evaluate the resulting flow path. Three-component velocity fields have been } \\
\text { captured using phase Doppler interferometry (PDI), and two-component velocity distributions using planar particle image velocimetry } \\
\text { (PIV). Data from these techniques have also offered insight into fuel drop size and distribution, fuel injector spray angle and pattern, } \\
\text { turbulence intensity, degree of vaporization and extent of reaction. This research serves to characterize operation of the baseline NASA 9- } \\
\text { point LDI strategy for potential use in future gas-turbine combustor applications. An additional motive is the compilation of a } \\
\text { comprehensive database to facilitate understanding of combustor fuel injector aerodynamics and fuel vaporization processes, which in turn } \\
\text { may be used to validate computational fluid dynamics codes, such as the National Combustor Code (NCC), among others. }\end{array}$} \\
\hline \multicolumn{6}{|c|}{$\begin{array}{l}\text { 15. SUBJECT TERMS } \\
\text { Laser diagnostics; Fuel injection; Fuel-air mixing; Aircraft gas turbine combustion; Velocity }\end{array}$} \\
\hline \multicolumn{3}{|c|}{ 16. SECURITY CLASSIFICATION OF: } & $\begin{array}{l}\text { 17. LIMITATION OF } \\
\text { ABSTRACT }\end{array}$ & $\begin{array}{l}\text { 18. NUMBER } \\
\text { OF }\end{array}$ & $\begin{array}{l}\text { 19a. NAME OF RESPONSIBLE PERSON } \\
\text { STI Help Desk (email:help@sti.nasa.gov) }\end{array}$ \\
\hline $\begin{array}{l}\text { a. REPORT } \\
\text { U }\end{array}$ & $\begin{array}{l}\text { b. ABSTRACT } \\
\text { U }\end{array}$ & $\begin{array}{l}\text { C. THIS } \\
\text { PAGE } \\
\text { U }\end{array}$ & UU & $\begin{array}{c}\text { PAGES } \\
19\end{array}$ & $\begin{array}{l}\text { 19b. TELEPHONE NUMBER (include area code) } \\
443-757-5802\end{array}$ \\
\hline
\end{tabular}



